\title{
Development of Stability Indicating RP-HPLC Method for Ertapenem in Bulk Drug and Pharmaceutical Dosage Form
}

\author{
Ruchi J ain ${ }^{1}$, Nilesh J ain ${ }^{2}$, Deepak Kumar J ain ${ }^{3}$, Avineesh Singh ${ }^{3}$ \\ and Surendra Kumar J ain ${ }^{1}$
}

\author{
${ }^{1}$ Sagar Institute of Research \& Technology-Pharmacy, Ayodhya Bypass Road \\ Bhopal-462041, (MP) India \\ ${ }^{2}$ Sagar Institute of Research Technology \& Sciences-Pharmacy, Ayodhya Bypass Road \\ Bhopal-462041, (MP) India \\ ${ }^{3}$ Medicinal Chemistry Research Laboratory, SLT Institute of Pharmaceutical Sciences, \\ Guru Ghasidas Central University, Bilaspur-495009, (CG) India
}

(Received: July 10, 2016; Accepted: February 01, 2017; Published (web): June 21, 2017)

\begin{abstract}
A simple, inexpensive, rapid and novel stability indicating isocratic HPLC method has been developed and validated for quantitative analysis of ertapenem sodium in the bulk drug and in pharmaceutical dosage form. An isocratic separation of ertapenem sodium was achieved on Hypersil BDS $C_{18}$ column (4.6 x 250 $\mathrm{mm}, 5 \mu$ particle size) as the stationary phase with a flow rate of $1.2 \mathrm{ml} / \mathrm{min}$ and using a UV detector to monitor the eluate at $298 \mathrm{~nm}$. The mobile phase consisted of acetonitrile : water (60:40v/v) and $\mathrm{pH}$ adjusted 2.9 by othophosphoric acid enabled separation of the drug from its degradation products. The method was validated for linearity, accuracy (recovery), precision, specificity and robustness. The linearity of the method was satisfactory over the range $2-10 \mu \mathrm{g} / \mathrm{ml}$ (correlation coefficient 0.999 ). Recovery of ertapenem sodium from the pharmaceutical dosage form ranged from 99.97 to $103.7 \%$. Ertapenem sodium was subjected to stress conditions [hydrolysis (acid, base), oxidation, photolysis and thermal degradation] and the samples were analyzed by this method. The forceddegradation study with ertapenem sodium showed that it was degraded under basic condition. The drug was stable under the other stress conditions investigated. Ertapenem sodium was found to be less stable in solution state, whereas it was comparatively much stable in solid state. The degradation products were well resolved from main peak. The forced degradation study prove the stability indicating power of the method and therefore, the validated method may be useful for routine analysis of ertapenem sodium as bulk drug, in respective dosage forms, for dissolution studies and as stability indicating assay method in pharmaceutical laboratories and industries.
\end{abstract}

Key words: RP-HPLC, Ertapenem sodium, forced degradation, method validated

\section{INTRODUCTION}

Ertapenem sodium (INVANZ, Merck, formerly MK-0826 and L-749,345) is chemically (4R, 5S, 6S)3-[(3S, 5S)-5-[(3-carboxyphenyl) carbamoyl] pyrrolidin-3-yl] sulfanyl-6-(1hydroxyethyl)-4methyl-7-oxo-1-azabicyclo [3.2.0] hept-2-ene-2carboxylic acid monosodium. Ertapenem sodium (Figure 1) a parenteral 1-methyl carbapenem (betalactam antibiotics), is structurally related to

Correspondence to: Deepak Kumar Jain

Email: jaindeepak2081@yahoo.com

Phone: +919424036795

Dhaka Univ. J. Pharm. Sci. 16(1): 21-28, 2017 (June) imipenem and meropenem and are widely used against a broad spectrum of aerobic and anaerobic Gram-positive and Gram-negative bacteria. Ertapenem sodium has been suggested as having potential use against Mycobacterium tuberculosis. ${ }^{1,2}$ Ertapenem sodium (ERP), approved by the FDA in 2001, is one of these carbapenems. Since ertapenem has an approximate half-life of 4 hrs, it can be administered once daily. Therefore, ERP can be favored above other carbapenems. ${ }^{3}$ Stability testing forms an important part of the process of drug product development. The purpose of stability testing 
is to provide evidence on how the quality of a drug substance or drug product varies with time under a variety of environmental conditions, for example temperature, humidity, light and enables storage conditions, retest periods and shelf life to be recommended. ${ }^{4,5}$ The two main aspects of study of the stability of a drug product that play an important role in shelf life determinations are assay of the active drug and the degradation products generated during stability studies. Assay of a drug product in a stability test sample must be performed with stabilityindicating method, as recommended by the International Conference on Harmonization (ICH). ${ }^{6}$ Literature survey revealed that a few analytical methods have been reported for the determination of ERP in pure drug, pharmaceutical dosage forms and in biological samples using UV visible spectroscopy ${ }^{7}$ and liquid chromatography. ${ }^{8}$ Several methods of liquid chromatography coupled to either UV absorbance or mass spectrometry detection have been developed for the quantification of ertapenem in human plasma. ${ }^{9-13} \mathrm{~A}$ LC-MS method was developed for the quantification of ERP in human plasma by detecting the deprotonated molecular ion of ERP under negative ionization mode with lower limit of quantification of 0.5 or $1 \mu \mathrm{g} / \mathrm{ml}$ and analytical run time of more than 5 min. ${ }^{14,15}$ LC-MS/MS methods have also been developed for the quantification of ertapenem on dried blood spot, ${ }^{16}$ microdialysate ${ }^{17}$ and human serum. ${ }^{18}$ None of the reported procedures enables analysis of the ERP alone in pharmaceutical dosage forms in the presence of their degradation products. This manuscript describes the development and validation, in accordance with ICH guidelines ${ }^{19}$ of a rapid, economical, precise and accurate stabilityindicating isocratic reversed phase HPLC method for analysis of ERP in the presence of its degradation products. This paper mainly deals with the forced degradation of ertapenem sodium under the stress conditions such as acidic \& basic hydrolysis, oxidation, heat, light and validation of the method for accurate quantification of ertapenem in the bulk drug \& pharmaceutical dosage form.

\section{EXPERIMENTAL}

Chemicals and reagents. Ertapenem sodium bulk drug (purity 98.9\%) was purchased from Merck Ltd. Mumbai, India and injection Ertazen (1 gm) was purchased from the local market. Acetonitrile (HPLC grade), othophosphoric acid, sodium hydroxide $(\mathrm{NaOH})$, hydrochloric acid $(\mathrm{HCl})$ and hydrogen peroxide $\left(\mathrm{H}_{2} \mathrm{O}_{2}\right)$ were obtained from Merck Fine Chemicals Mumbai, India. Double HPLC grade water was used throughout the experiment. Other chemicals used were of analytical or HPLC grade. Standard stock solution (1 $\mathrm{mg} / \mathrm{ml})$ of ERP was prepared by dissolving the working standard in HPLC grade water and diluting with the same solvent. Standard calibration solutions $(2-10 \mu \mathrm{g} / \mathrm{ml})$ for assessment of linearity were prepared from this stock solution by dilution with diluent.

Chromatography. A high performance liquid chromatographic system from Young Lin 9100 comprising of manual injector, YL 9111 quaternary pump for constant flow and constant pressure delivery and Photodiode array detector (YL 9160 detector) connected to software YL clarity for controlling the instrumentation as well as processing the data generated was used. The chromatographic analysis was performed by using a mobile phase of acetonitrile: water $(60: 40 \mathrm{v} / \mathrm{v}), \mathrm{pH}$ adjusted 2.9 by othophosphoric acid. These were filtered through $0.45 \mu$ membrane filter and degassed by sonication before use. The mobile phase was pumped isocratically at a flow rate of $1.2 \mathrm{ml} / \mathrm{min}$ during analysis at ambient temperature. The run time was set at $10 \mathrm{~min}$ and the volume of injection was $20 \mu \mathrm{l}$ and eluent was detected at $298 \mathrm{~nm}$ on a Hypersil BDS $\mathrm{C}_{18}$ column (4.6 x $250 \mathrm{~mm}, 5 \mu$ particle size).

Analysis of dosage form. A volume of the injection equivalent to $100 \mathrm{mg}$ of ERP were weighed into a $100 \mathrm{ml}$ volumetric flask, $50 \mathrm{ml}$ of diluents was added and shaken thoroughly for about 10 minutes, then the volume was made up to the mark with the diluents, mixed well and filtered. Further dilutions were made and the assay of injections was completed according to general procedure. 
Forced degradation study. To study the effect of acid, accurately weighed $10 \mathrm{mg}$ ERPWS was dissolved in $9 \mathrm{ml}$ water (HPLC) and volume was made up to $10 \mathrm{ml}$ with $1 \mathrm{~N} \mathrm{HCl}$ to get a concentration of $1000 \mu \mathrm{g} / \mathrm{ml}$ (i.e conc. of $\mathrm{HCl}$ in solution was 0.1 $\mathrm{N})$ and kept on water bath at $80^{\circ} \mathrm{C}$ for $60 \mathrm{~min}$. Aliquots of above solution was neutralized with $1 \mathrm{~N}$ $\mathrm{NaOH}$ and diluted with diluents to get $6 \mu \mathrm{g} / \mathrm{ml}$ solution. The sample solution was analyzed and chromatogram was recorded. To study the effect of alkali, accurately weighed $10 \mathrm{mg}$ of ERPWS was dissolved in $9 \mathrm{ml}$ water (HPLC) and volume made up to $10 \mathrm{ml}$ with $1 \mathrm{~N}$ sodium hydroxide to achieve the solution of $1000 \mu \mathrm{g} / \mathrm{ml}$ (i.e. conc. of $\mathrm{NaOH}$ in solution was $0.1 \mathrm{~N}$ ). The above mixture was kept on a boiling water bath at $80^{\circ} \mathrm{C}$ for $60 \mathrm{~min}$. Aliquots of above solution was neutralized with $1 \mathrm{~N} \mathrm{HCl}$ and diluted with diluents to get $6 \mu \mathrm{g} / \mathrm{ml}$ solution. The sample solution was analyzed and chromatogram was recorded. To study the effect of oxidizing conditions, accurately weighed about $10 \mathrm{mg}$ ERPWS was dissolved in $9 \mathrm{ml}$ water (HPLC) and volume was made up to $10 \mathrm{ml}$ with $30.0 \%$ hydrogen peroxide to achieve a solution of $1000 \mu \mathrm{g} / \mathrm{ml}$ (i.e. conc. of hydrogen peroxide in solution was 3\%) and kept on water bath at $80^{\circ} \mathrm{C}$ for $60 \mathrm{~min}$. Aliquots of above solution was neutralized with $1 \mathrm{~N} \mathrm{HCl}$ and diluted with diluents to get $6 \mu \mathrm{g} / \mathrm{ml}$ solution. The sample solution was analyzed and chromatogram was recorded. To study the effect of temperature, accurately weighed about $1.0 \mathrm{~g}$ ERP WS was kept at $80^{\circ} \mathrm{C}$ in oven for 3 days. Sample equivalent to $10 \mathrm{mg}$ of drug was withdrawn after every 24 hour and diluted as per the procedure. Aliquots of $6 \mu \mathrm{g} / \mathrm{ml}$ concentration were prepared and chromatogram was recorded. To study the effect of UV light, accurately weighed about $1.0 \mathrm{~g}$ ERP WS was exposed to short and long wavelength UV light (222 and $366 \mathrm{~nm}$, respectively) for $48 \mathrm{hrs}$, Sample equivalent to $10 \mathrm{mg}$ of drug was withdrawn after every $24 \mathrm{hrs}$ and diluted as per the procedure. Aliquots of $6 \mu \mathrm{g} / \mathrm{ml}$ concentration were prepared and chromatogram was recorded.

\section{METHOD VALIDATION}

The method was validated for linearity, specificity, limits of detection (LOD) and quantification (LOQ), system suitability, accuracy, precision, robustness and stability in accordance with ICH guidelines. To assess specificity, peak purity was determined by use of the photodiode-array detector. To check linearity, test solutions of ERP were prepared at six concentrations 2-10 $\mu \mathrm{g} / \mathrm{ml}$. Each solution was injected in triplicate and calibration graphs were obtained by plotting peak area against concentration. Linearity was checked over the same concentration range on three consecutive days. RSD (\%) of the slope and Y-intercept of the calibration plot were also calculated. The limits of detection (LOD) and quantification (LOQ) for ertapenem were determined, as the amounts for which signal-to-noise ratios were 3:1 and 10:1, respectively, by injecting a series of dilute solutions of known concentration. Precision, as RSD (\%) was determined by measuring the concentration of drug in the injection six times. Intermediate (inter-day) precision was evaluated by two analysts on different days in the same laboratory. The accuracy of the method was studied by measurement of recovery after adding known amounts of the drug (80, 100 and $120 \%$ of the label claim of 1gm ertapenem sodium per injection) to the placebo. Three samples were prepared for each recovery level and results were calculated by use of the calibration plot. The robustness of the method was assessed by deliberate alteration of the experimental conditions and determining the effect on resolution of ERP from the main product obtained by degradation under basic conditions. The change was made in the ratio of mobile phase, instead of acetonitrile: water $(60: 40 \mathrm{v} / \mathrm{v}) \mathrm{pH}$ adjusted 2.9 by othophosphoric acid, acetonitrile: 1 water $(65: 35 \mathrm{v} / \mathrm{v})$ pH adjusted 2.9 by othophosphoric acid was used as a mobile phase and flow rate, instead of $1.2 \mathrm{ml} / \mathrm{min}$, $0.8 \mathrm{ml} / \mathrm{min}$ and $1.0 \mathrm{ml} / \mathrm{min}$. During these tests all other conditions were held constant at the optimum values. The stability of ERP and sample solutions (at ambient temperature) were tested by analysis after 24, 48 and 72 hrs, comparison of the results with 
those obtained from freshly prepared standard solutions and calculation of RSD.

\section{RESULTS AND DISCUSSION}

Optimization of chromatographic conditions. The primary objective in developing this stability indicating HPLC method were to achieve resolution between ERP and its degradation products. To achieve this, Young Lin 9100 with YL 9160 detector and C18 column was employed for envisaged work. Combination of acetonitrile: water $(60: 40 \mathrm{v} / \mathrm{v}) \mathrm{pH}$ adjusted 2.9 by othophosphoric acid as mobile phase was attempted for quantitation of ERP with acceptable system suitability parameters (RT, tailing factor, number of theoretical plates and HETP) at 298 $\mathrm{nm}$ as detection wavelength. Linearity was found 0$10 \mu \mathrm{g} / \mathrm{ml}$ with correlation coefficient $\mathrm{r}^{2}=0.9997$ having equation as: $\mathrm{AUC}=28605$ Conc. +14629 . The column temperature was $25^{\circ} \mathrm{C}$. The tailing factor for ertapenem was $<2$ and retention times were approximately $6.67 \pm 0.5 \mathrm{~min}$ for main peak and less than $10 \mathrm{~min}$ for the degradation products (Figure 2). This low total runs time resulted in high productivity and low cost of analysis as per sample.

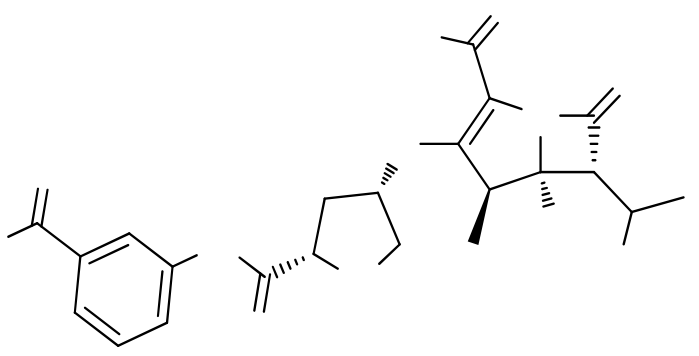

Figure 1. Molecular structure of ertapenem sodium

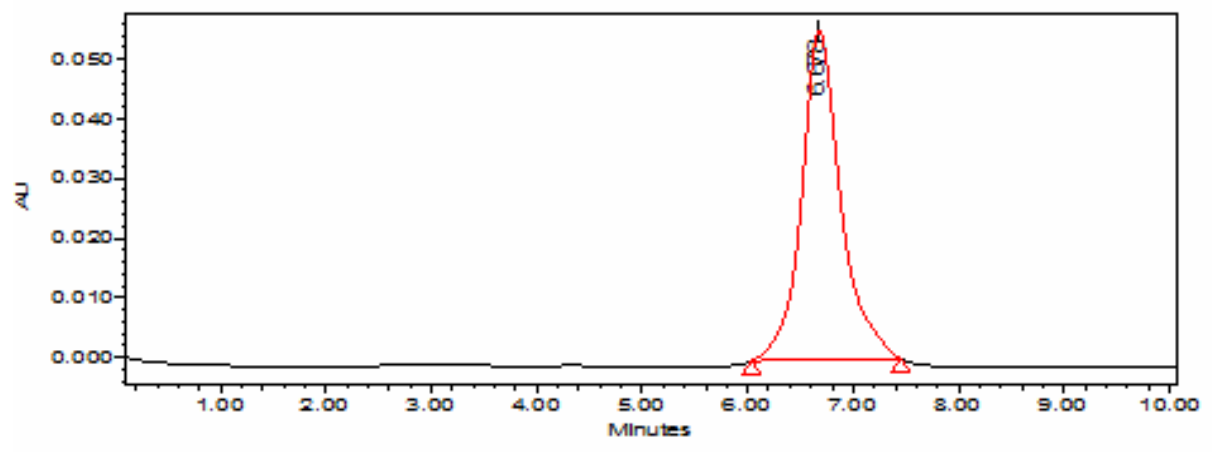

Figure 2. Standard chromatogram of ertapenem sodium

Forced degradation study. Bakshi et al. ${ }^{20}$ suggested target degradation of $20-80 \%$ when establishing the stability-indicating properties of analytical methods, because even intermediate degradation products should not interfere with any stage of drug analysis. Although conditions used for forced degradation were adjusted to achieve degradation in this range, this could not be achieved for conditions other than exposure to acid, base and oxidising agent, even after long exposure. Peak purity test results confirmed that the ertapenem peak was homogeneous under all the stress conditions tested. The mass balance of ERP in stress samples was close to $100 \%$ and, moreover, assay of unaffected ERP in the injection confirmed the stability-indicating nature of the method. The results from fo ced degradation studies are summarised in table 1. Chromatographic peak-purity data were obtained from the spectral analysis report; pe $\mathbf{k}$ greater than 99 is indicative of a homogeneous peak. The peak purity 


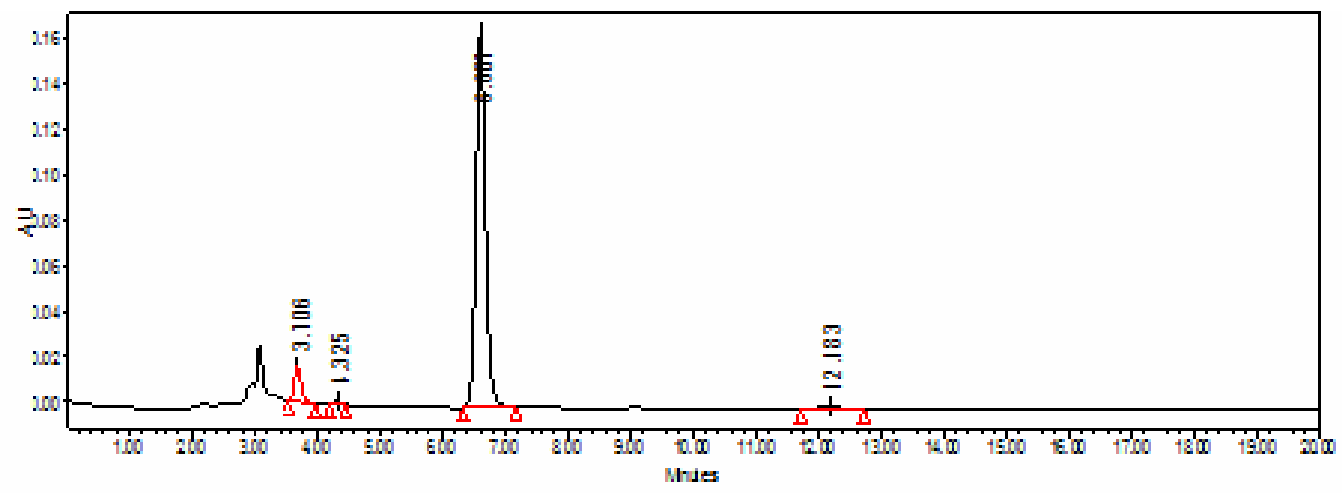

(A)

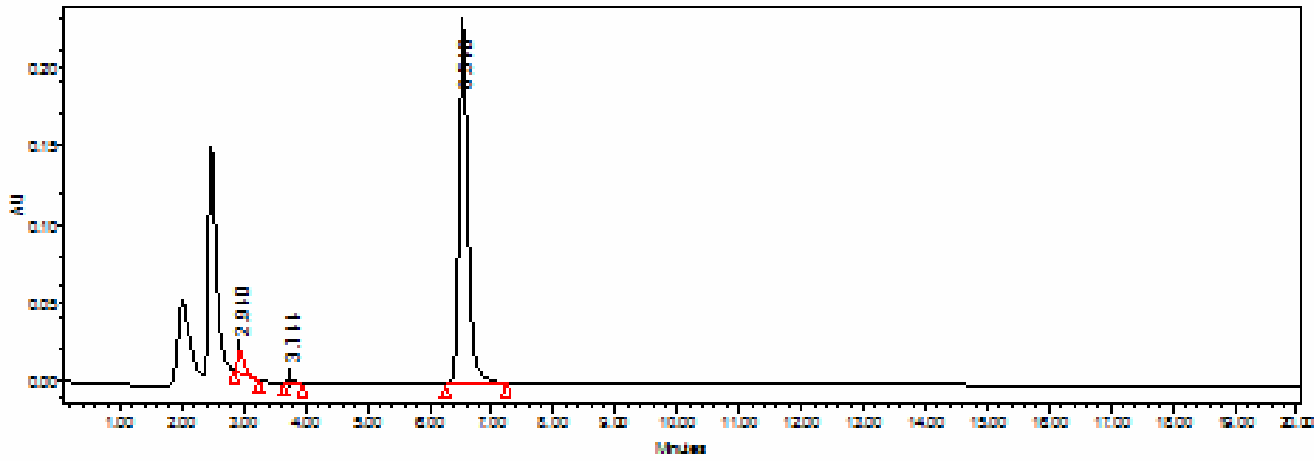

(B)

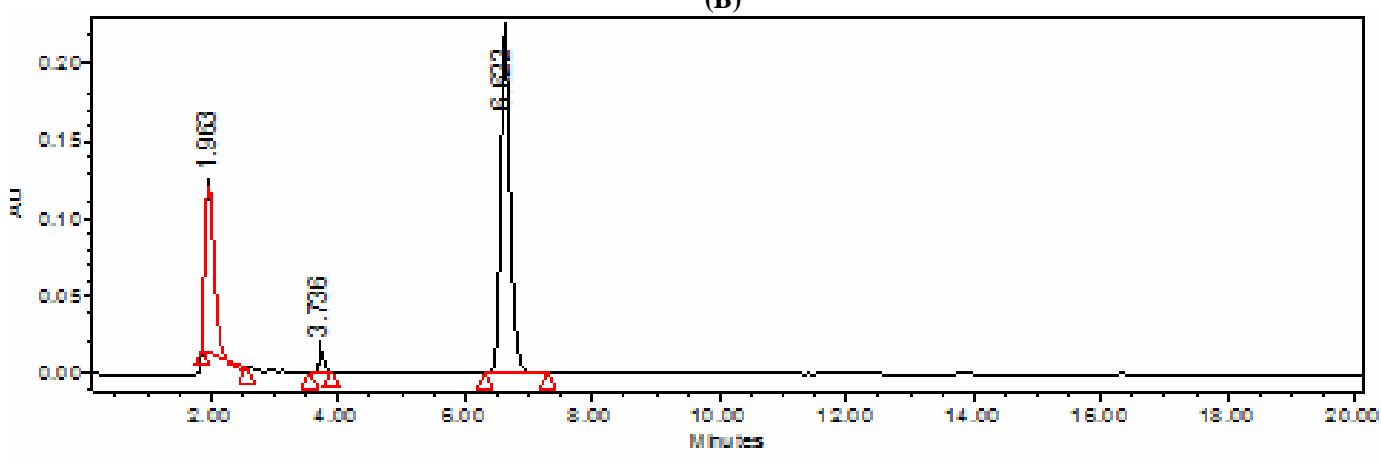

(C)

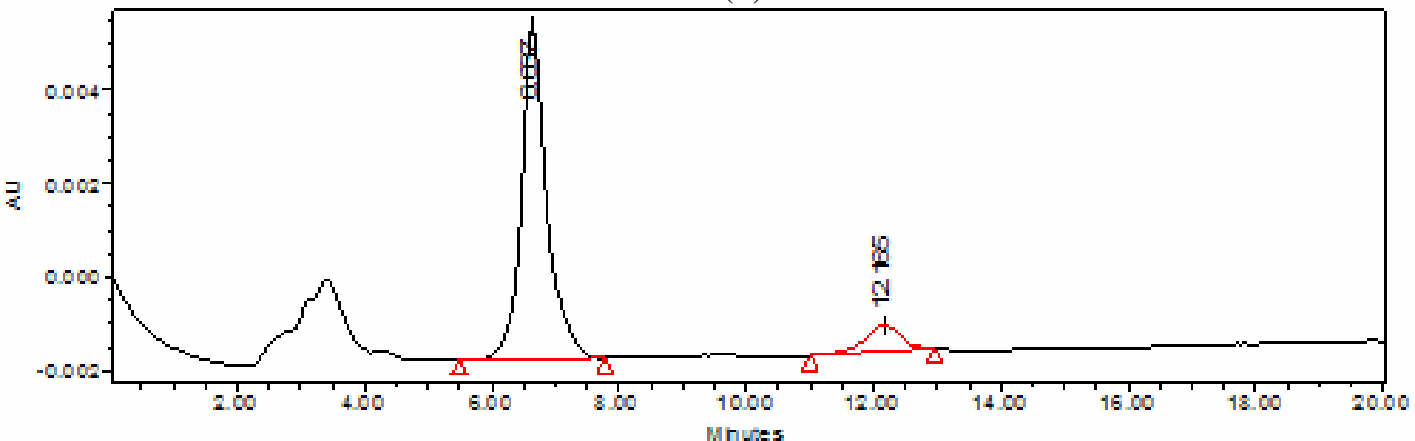

(D)

Figure 3. Typical chromatogram obtained after degradation of ertapenem sodium under (A) acidic conditions, (B) basic conditions, (C) oxidising conditions, (D) photolytic condition 
for ERP from degradation studies was in the range 99.9-100.0, indicating homogeneous peaks and thus establishing the specificity of the method. Chromatograms from the solutions obtained after degradation under acidic, basic, oxidising, photolytic conditions are shown in Figure 3, respectively. No peaks co-eluted with the ERP peak, suggesting the method enabled specific analysis of ertapenemin the presence of its degradation products.

Table 1. Results from analysis of samples from the forced degradation study, showing percentage degradation and peak purity of ertapenem sodium.

\begin{tabular}{lcc}
\hline Stress condition and duration & $\begin{array}{c}\% \\
\text { degradation }\end{array}$ & $\begin{array}{c}\text { Peak } \\
\text { purity* }\end{array}$ \\
\hline $\begin{array}{l}\text { Acid degradation } 0.1 \mathrm{~N} \mathrm{HCl}-80^{\circ} \mathrm{C} \\
\text { /60 min }\end{array}$ & 4.8 & 99.928 \\
$\begin{array}{l}\text { Base degradation } 0.1 \mathrm{~N} \mathrm{NaOH} \mathrm{-} \\
80^{\circ} \mathrm{C} / 60 \text { min }\end{array}$ & 88.45 & 99.983 \\
oxidizing degradation $\left(3 \% \mathrm{H}_{2} \mathrm{O}_{2}\right)-$ & 21.2 & 99.912 \\
60 min & & \\
$\begin{array}{l}\text { Thermal degradation- } 80^{\circ} \mathrm{C} / 48 \mathrm{hrs} \\
\mathrm{UV} \text { light } / 222 \mathrm{~nm} / 48 \mathrm{~h}\end{array}$ & 6.9 & 99.971 \\
UV light/366nm/48 h & 10.3 & 99.931 \\
\hline
\end{tabular}

*Peak purity values in the range of 99-100 indicate a homogeneouspeak

Table 2. Results from regression analysis and system suitability data.

\begin{tabular}{lc}
\hline Parameters & Ertapenem \\
\hline Retention time* & $6.67 \pm 0.5 \mathrm{~min}$ \\
Tailing factor* & 1.13 \\
Theoretical plate* & 1406733 \\
Linear range $(\mu \mathrm{g} / \mathrm{ml})$ & $2-10$ \\
limits of detection $(\mu \mathrm{g} / \mathrm{ml})$ & 0.05 \\
limits of quantification $(\mu \mathrm{g} / \mathrm{ml})$ & 0.21 \\
Linear equation & 28605 conc. +14629 \\
Slope & 28605 \\
Intercept & 14629 \\
Correlation coefficient & 0.9997 \\
S.D. of slope & 836.4 \\
$\%$ RSD of slope & 0.084 \\
S.D. of intercept & 13266 \\
$\%$ RSD of intercept & 0.212 \\
\hline
\end{tabular}

*Mean of six readings
Table 3. Result of precision of test method of ertapenem sodium.

\begin{tabular}{|c|c|c|c|}
\hline \multirow{2}{*}{$\begin{array}{l}\text { Std. conc. } \\
(\mu \mathrm{g} / \mathrm{ml})\end{array}$} & \multirow[t]{2}{*}{ Repeatability } & \multicolumn{2}{|c|}{ Intermediate precision } \\
\hline & & Day to day & $\begin{array}{l}\text { Analyst } \\
\text { analyst }\end{array}$ \\
\hline 2 & 100.2 & 99.80 & 99.26 \\
\hline 4 & 102.7 & 103.9 & 100.19 \\
\hline 6 & 99.60 & 102.3 & 99.80 \\
\hline 8 & 101.00 & 100.5 & 99.02 \\
\hline 10 & 100.19 & 100.9 & 100.12 \\
\hline Mean & 100.738 & 101.48 & 99.67 \\
\hline S.D. & 1.205 & 1.632 & 0.519 \\
\hline \% R.S.D. & 1.196 & 1.608 & 0.520 \\
\hline \multicolumn{4}{|c|}{$\begin{array}{l}\text { *Mean of fifteen determinations ( } 3 \text { replicates at } 5 \text { concentratic } \\
\text { level) }\end{array}$} \\
\hline \multicolumn{4}{|c|}{ Table 4. Recovery of ertapenem sodium. } \\
\hline $\begin{array}{l}\text { Level of } \\
\text { addition }\end{array}$ & \multicolumn{2}{|c|}{$\begin{array}{l}\text { Std. drug sol. added } \\
\qquad(\mu \mathrm{g} / \mathrm{ml})\end{array}$} & $\begin{array}{l}\% \text { mean* } \\
\text { recovered }\end{array}$ \\
\hline 80 & \multicolumn{2}{|l|}{2} & 103.7 \\
\hline 100 & \multicolumn{2}{|l|}{4} & 101.1 \\
\hline 120 & \multicolumn{2}{|l|}{6} & 99.97 \\
\hline
\end{tabular}

*Average of five determination

Table 5. Results from robustness testing.

\begin{tabular}{lcc}
\hline Parameter & $\begin{array}{c}\text { Percentage } \\
(\text { Mean } \pm \text { S.D*.) }\end{array}$ & $\begin{array}{c}\text { Percentage } \\
\text { RSD* }\end{array}$ \\
\hline Mobile phase & $97.24 \pm 0.17$ & 0.179 \\
Flow rate & $98.40 \pm 0.09$ & 0.091 \\
\hline
\end{tabular}

*Mean obtained at three concentrations and three replicate

Method validation. Peak purity was $>99.9 \%$ for drug substance and drug degradation products at 298 $\mathrm{nm}$, which showed that the analyte peaks were pure and that formulation excipients and degradation products were not interfering with analyte peaks. LOD and LOQ for ERP were 0.05 and $0.21 \mu \mathrm{g} / \mathrm{ml}$, respectively, for $20 \mu \mathrm{l}$ injection volume. Results from regression analysis are listed in table 2, with system suitability data. When precision was determined by six fold analysis of drug injection, the RSD of ERP peak area was less than $2 \%$, indicating that the method is reliable. Results from assessment of precision are listed in table 3 . Results obtained from determination of recovery are listed in table 4 and results from robustness testing are shown in table 5. 


\section{CONCLUSION}

The method developed for quantitative analysis of ertapenem sodium is rapid, precise, accurate and selective. Peak purity studies under all the stress conditions showed the drug peak to be pure and hence the method is stability indicating. In other words it can be mentioned that the method developed can be utilized for the successful quantification of the drug in presence of its degradation product and excipients. The method was completely validated and satisfactory results were obtained for all the characteristics tested. The method is stabilityindicating and can be used to assess the stability of ertapenem sodium in the bulk drug. The method can be conveniently used for routine analysis of ertapenem sodium as bulk drug, in respective dosage forms, for dissolution studies and as stability indicating assay method in pharmaceutical laboratories and industries.

\section{Conflict of interest}

The authors declare no conflict of interest.

\section{REFERENCES}

1. Hugonnet, J.E., Tremblay, L.W., Boshoff, H.I., Barry, C.E. and Blanchard, J.S. 2009. Meropenem-clavulanate is effective against extensively drug resistant mycobacterium tuberculosis. Sci. 323, 1215-1218.

2. Gupta, R., Lavollay, M., Mainardi, J.L., Arthur, M., Bishai, W.R. and Lamichhane, G. 2010. The mycobacterium tuberculosis protein LdtMt2 is a nonclassical transpeptidase required for virulence and resistance to amoxicillin. Nat. Med.16, 466-469.

3. Majumdar, A. K., Musson, D. G., Birk, K. L., Kitchen, C.J., Holland, S., McCrea, J., Mistry, G., Hesney, M., Xi, L., Li, S. X., Haesen, R., Blum, B. A., Lins, R.L., Greenberg, H., Waldman, S., Deutsch, P. and Rogers, J.D. 2002. Pharmacokinetics of ertapenem in healthy young volunteers. Antimicrob. Agents Chemother. 46, 3506-3511.

4. Pugh, J. 2002. Kinetics and product stability, the science of dosage form design, Aulton, M.E. (Eds.). Churchill Livingstone, London, p.109.

5. Carstensen, J.T. 1995. Modus operendi for stability programme, drug stability and practices. Marcel Dekker, Inc. New York. p. 487.
6. International conference on harmonization of technical requirements for registration of pharmaceuticals for human use, stability testing of new drug substances and products. QIA (R2), August, 2003.

7. Babu,K.R., Kumari, N.A. and Lakshmi, R.V. 2014. Spectrophotometric determination of ertapenem in bulk and injection formulations by $p$-dimethyl amino benzaldehyde (pdab). Int. J. Anal. Pharm. Biom. Sci. 3, 11-17.

8. Vempati, P., Kusuma,J. and Rao, M.V.B. 2015. Development of validated RP-HPLC method for the determination of ertapenem in spiked human plasma. Int. J. Adv. Pharma. Sci. 6, 2861-2864.

9. Dailly, E., Bouquie, R., Deslandes, G., Jolliet, P. and Le Floch, R. 2011. A liquid chromatography assay for a quantifiation of doripenem, ertapenem, imipenem, meropenem concentrations in human plasma: application to a clinical pharmacokinetic study. J. Chromatogr. B.879, 11371142.

10. Mundkowski, R.G., Majcher-Peszynska, J., Burkhardt, O., Welte, T. and Drewelow, B. 2006. A new simple HPLC assay for the quantifiation of ertapenem in human plasma, lung tissue and broncho-alveolar lavage flid. J. Chromatogr. B. 832, 231-235.

11. McWhinney, B.C., Wallis, S.C., Hillister, T., Roberts, J.A., Lipman, J. and Ungerer, J.P. 2010. Analysis of 12 beta-lactam antibiotics in human plasma by HPLC with ultravioletdetection. J. Chromatogr. B. 878, 2039-2043.

12. Legrand, T., Chhun, Rey, E. Blanchet, B., Zahar, J.R., Lanternier, F., Pons, G. and Jullien, V. 2008. Simultaneous determination of three carbapenem antibiotics in plasma by HPLC withultraviolet detection. J. Chromatogr. B. 875, 551-556.

13. Van Rijn, S.P., Wessels, A.M.A., Greijdanus, B., Touw, D.J. and Alffenaar, J.W.C. 2014. Quantification and validation of ertapenem using a liquid chromatography-tandem mass spectrometry method. Antimicrob. Agents Chemother. 58, 3481-3484.

14. Koal, T., Deters, M., Resch, K. and Kaever, V. 2006. Quantifiation of the carbapenemantibiotic ertapenem in human plasma by a validated liquid chromatography mass spectrometry method. Clin. Chim. Acta. 364, 239-245.

15. Pickering, M. and Brown, S. 2013.Quantifiation and validation of HPLC-UV and LC-MS assays for therapeutic drug monitoring of ertapenem in human plasma. Biomed. Chromatogr. 27, 568-574.

16. La Marca, G., Giocaliere, E., Villanelli, F., Malvagia, S., Funghini, S., Ombrone, D., Filippi, L., De Gaudio, M.,De Martino,M. and Galli,L. 2012. Development of an UPLCMS/MS method for the determination of antibiotic ertapenem on dried blood spots. J. Pharm. Biomed. Anal.61, 108-113. 
17. Lefeuvre, S., Venisse, N., Marchand, S., Bachelet, M. and Couet, W. 2008. A simpleand sensitive liquid chromatography-tandem mass spectrometry assay for the quantifiation of ertapenem in microdialysate. J. Chromatogr. B. 862, 242-245.

18. Hee, K.H., Fisher, D., Tam, V.H. and Soon-U Lee, L. 2015. Development and validation of liquid chromatographytandem mass spectrometry method for the quantification of ertapenem in human serum, Pharm. Anal. Acta. 6, 2-5.
19. Drug information branch (hfd-210), validation of analytical procedure: methodology. Step 4. In: ICH harmonized tripartite guidelines Q2B. center for drug evaluation and research, Rockville MD, 6 Nov, 1996.

20. Bakshi, M., Singh, B., Singh, A. and Singh, S. 2001. The ICH guidance in practice: Stress degradation studies on ornidazole and development of a validated stability-indicating assay. $J$. Pharm. Biomed. Anal. 26, 891-897. 